\title{
Whipple's Disease with Long-term Endoscopic Follow-up
}

\author{
Hiroaki Saito ${ }^{1,2}$, Junji Shiode ${ }^{1}$, Shogen Ohya ${ }^{1,3}$, Atsushi Yao ${ }^{4}$, Shunsuke Saito ${ }^{1}$, \\ Masakuni Fujii ${ }^{1}$, Mamoru Itoh ${ }^{1}$, Shuhei Ishiyama ${ }^{1}$, Akiko Fujiwara ${ }^{1}$, Junichiro Nasu ${ }^{1}$, \\ Masao Yoshioka ${ }^{1}$ and Kazuhide Yamamoto ${ }^{1}$
}

\begin{abstract}
:
A 72-year-old man presented with anorexia and 15-kg weight loss over 3 years. Endoscopy revealed yellow, shaggy mucosa alternating with erythematous, eroded mucosa in the duodenum. Biopsy specimens showed massive infiltration of periodic acid-Schiff-positive macrophages in the lamina propria, consistent with Whipple's disease. The patient was treated with intravenous ceftriaxone for four weeks, followed by oral trimethoprim-sulfamethoxazole. His condition improved, and he gradually gained weight. Although the endoscopic findings improved with continuous trimethoprim-sulfamethoxazole administration, macrophage infiltration of the duodenal mucosa persisted. However, the patient has been symptom-free for eight years.
\end{abstract}

Key words: Whipple's disease, Tropheryma whipplei, endoscopy, macrophage

(Intern Med 57: 1707-1713, 2018)

(DOI: 10.2169/internalmedicine.9631-17)

\section{Introduction}

Whipple's disease is a systemic inflammatory condition resulting from infection with the bacterium Tropheryma whipplei. It typically involves the duodenum and small intestine, causing severe malabsorption. It can also affect many organs, including the heart and brain, and is occasionally fatal (1). Whipple's disease is rare, with only about 1,000 cases reported to date (2), some of which have been reported in Japan. We herein report the endoscopic and histopathologic findings over eight years in a patient with Whipple's disease.

\section{Case Report}

A 72 year-old-man had a history of anorexia and general malaise beginning in the summer of 2005. Although he consulted a local doctor and was treated with intravenous feeding, his symptoms gradually worsened. He lost $15 \mathrm{~kg}$ over 3 years and became unable to walk. He consulted our hospital for further investigations and was admitted in April 2008.

The patient had a history of abdominal surgery for intesti- nal volvulus at the age of 14 years. Physical examination findings on admission were as follows: height, $173 \mathrm{~cm}$; body weight, $49.2 \mathrm{~kg}$; body mass index, $16.4 \mathrm{~kg} / \mathrm{m}^{2}$; body temperature, $36.9^{\circ} \mathrm{C}$, blood pressure, $124 / 86 \mathrm{mmHg}$; and pulse, 60 beats/minute. He was alert, and a neurological examination showed normal findings. His respiratory and cardiac sounds and abdominal findings were normal. His laboratory data on admission are summarized in Table 1 . He demonstrated hypoalbuminemia and high levels of Creactive protein, soluble interleukin-2 receptor (sIL-2R), and interleukin-6 (IL-6).

Abdominal computed tomography showed thickening of the small intestinal mucosa and lymphadenopathy in the abdominal cavity. Although upper gastrointestinal endoscopy showed yellow-white, shaggy mucosa in the duodenum, biopsy specimens did not reveal any specific findings.

After admission, he was treated with intravenous hyperalimentation, but his symptoms worsened. Because of the high sIL-2R and IL-6 levels and abdominal lymphadenopathy, we suspected Castleman's disease and started oral prednisolone $25 \mathrm{mg}$ daily. His appetite improved and his weight increased, so he was discharged from the hospital on day 33. However, he lost his appetite again and was readmitted 1

${ }^{1}$ Department of Internal Medicine, Okayama Saiseikai General Hospital, Japan, ${ }^{2}$ Saito Clinic, Japan, ${ }^{3}$ Kawaguchi-Medical Clinic, Japan and ${ }^{4}$ Department of Internal Medicine (Nephrology), Kanto Rosai Hospital, Japan

Received: June 7, 2017; Accepted: October 15, 2017; Advance Publication by J-STAGE: February 9, 2018

Correspondence to Dr. Hiroaki Saito, gentetu3110@gmail.com 
month later.

We performed repeat upper gastrointestinal endoscopy, which revealed yellow, shaggy mucosa alternating with erythematous, eroded mucosa in the duodenum (Fig. 1). Biopsy specimens revealed massive infiltration of periodic acid-Schiff (PAS)-positive macrophages in the lamina propria of the duodenum, while electron microscopy revealed bacillus-like bodies in the lamina propria (Fig. 2). We recognized these characteristic endoscopic and pathologic findings of Whipple's disease and started treatment with ceftriaxone (CTRX) 2 g daily.

His appetite gradually increased and his general condition

Table 1. Laboratory Data on Admission.

\begin{tabular}{lclc}
\hline WBC & $5,030 / \mu \mathrm{L}$ & $\mathrm{Cl}$ & $104 \mathrm{mmol} / \mathrm{L}$ \\
Neu & $71.6 \%$ & AST & $33 \mathrm{IU} / \mathrm{L}$ \\
Eos & $1.2 \%$ & ALT & $31 \mathrm{IU} / \mathrm{L}$ \\
Baso & $0.4 \%$ & ALP & $146 \mathrm{IU} / \mathrm{L}$ \\
Lym & $25.0 \%$ & $\gamma$-GTP & $11 \mathrm{IU} / \mathrm{L}$ \\
Mono & $1.8 \%$ & ChE & $64 \mathrm{IU} / \mathrm{L}$ \\
RBC & $237 \times 10^{4} / \mu \mathrm{L}$ & LDH & $201 \mathrm{IU} / \mathrm{L}$ \\
$\mathrm{Hgb}$ & $6.6 \mathrm{~g} / \mathrm{dL}$ & T-bil & $0.4 \mathrm{mg} / \mathrm{dL}$ \\
$\mathrm{Hct}$ & $20.3 \%$ & D-bil & $0.1 \mathrm{mg} / \mathrm{dL}$ \\
$\mathrm{PLT}$ & $16.5 \times 10^{4} / \mu \mathrm{L}$ & BUN & $11.5 \mathrm{mg} / \mathrm{dL}$ \\
TP & $4.9 \mathrm{~g} / \mathrm{dL}$ & Cr & $0.69 \mathrm{mg} / \mathrm{dL}$ \\
Alb & $2.1 \mathrm{~g} / \mathrm{dL}$ & CEA & $1.1 \mathrm{ng} / \mathrm{mL}$ \\
$\mathrm{CRP}$ & $2.75 \mathrm{mg} / \mathrm{dL}$ & CA19-9 & $8.2 \mathrm{U} / \mathrm{mL}$ \\
$\mathrm{Na}$ & $133 \mathrm{mmol} / \mathrm{L}$ & $\mathrm{sIL}-2 \mathrm{R}$ & $1,950 \mathrm{U} / \mathrm{mL}$ \\
$\mathrm{K}$ & $3.8 \mathrm{mmol} / \mathrm{L}$ & $\mathrm{IL}-6$ & $20.7 \mathrm{pg} / \mathrm{mL}$ \\
\hline
\end{tabular}

WBC: white blood cells, Neu: neutrophils, Eos: eosinophils, Baso: basophils, Lym: lymphocytes, Mono: monocytes, RBC: red blood cells, Hgb: hemoglobin, Hct: hematocrit, PLT: platelets, TP: total protein, Alb: albumin, CRP: C-reactive protein, Na: sodium, K: potassium, $\mathrm{Cl}$ : chloride, AST: aspartate aminotransferase, ALT: alanine aminotransferase, ALP: alkaline phosphatase, $\gamma$-GTP: gamma-glutamyl transpeptidase, ChE: cholinesterase, LDH: lactic acid dehydrogenase, T-bil: total bilirubin, D-bil: direct bilirubin, BUN: blood urea nitrogen, Cr: creatinine, CEA: carcinoembryonic antigen, CA: cancer antigen, sIL: soluble interleukin, IL: interleukin improved after starting treatment. We performed additional gastrointestinal endoscopy on day 17, which showed remarkable improvement, although the yellow, shaggy mucosa remained. He remained symptom-free, so we switched to oral trimethoprim-sulfamethoxazole (TMP-SMX) 1,920 mg daily, and the patient was discharged from the hospital on day 32.

He continued oral TMP-SMX after discharge and remained symptom-free and gradually gained weight. His course after starting treatment is shown in Fig. 3. We have followed him with yearly upper gastrointestinal endoscopy, the findings of which are shown in Fig. 4. Although the changes in the duodenal mucosa improved during the early stages of treatment, PAS-positive macrophage infiltration of the lamina propria has persisted, even eight years after starting treatment (Fig. 5). Although the clinical significance of these findings is not clear, we have continued TMP-SMX to prevent disease recurrence.

\section{Discussion}

Whipple's disease is a multisystem inflammatory condition resulting from infection with the bacterium T. whipplei. Whipple's disease is rare, with a prevalence thought to be less than $0.1 \%$ (3). The disorder mostly affects middle-aged white men and is very rare in Asian countries. The Japanese case reports of Whipple's disease from 1970 to 2016 that we searched in PubMed MEDLINE and Japanese Medical Abstract Society databases are summarized in Table 2. 12 cases (including our case) have been reported in the literature (4-14). Four additional cases have been reported in abstract form only (15-18). In most of the Japanese cases, the patients were middle-aged (over 50 years of age), but there have also been a few reports involving younger patients.

Whipple's disease was first described by George $\mathrm{H}$. Whipple in 1907 (19). In 1949, PAS-positive macrophages were found to have infiltrated the lamina propria of the small intestine in patients with the disease (20). The bacte-

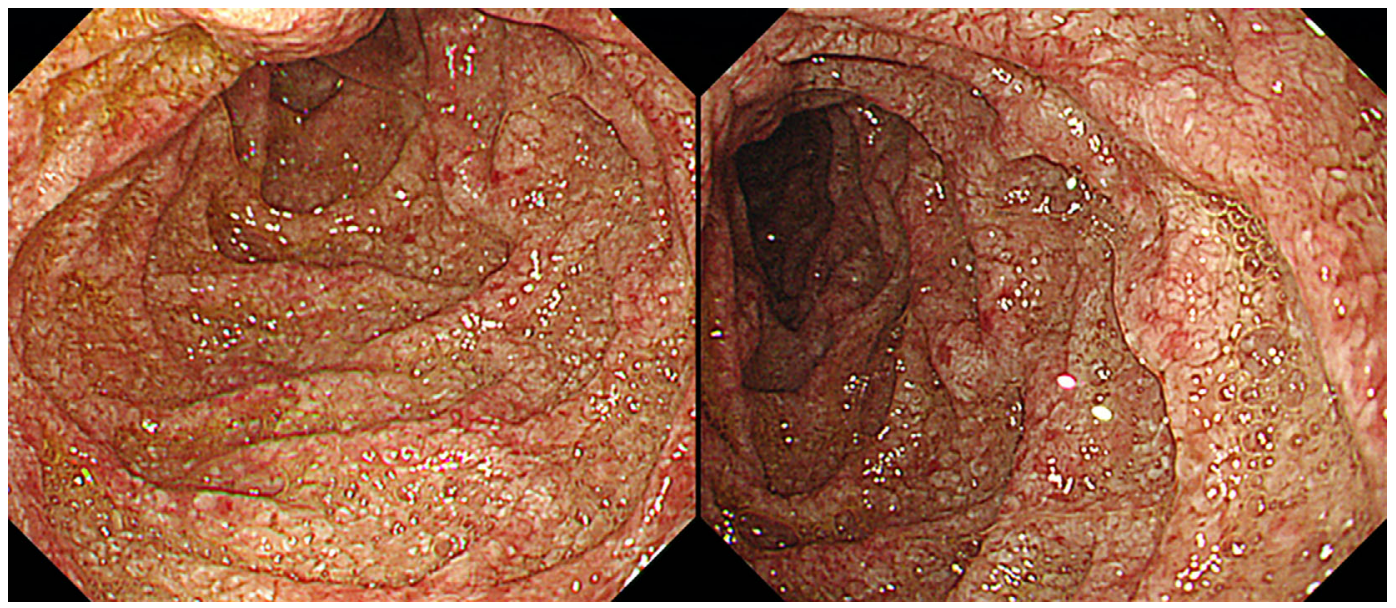

Figure 1. Upper gastrointestinal endoscopy on readmission. Yellow, shaggy mucosa alternating with erythematous, eroded mucosa in the duodenum. 


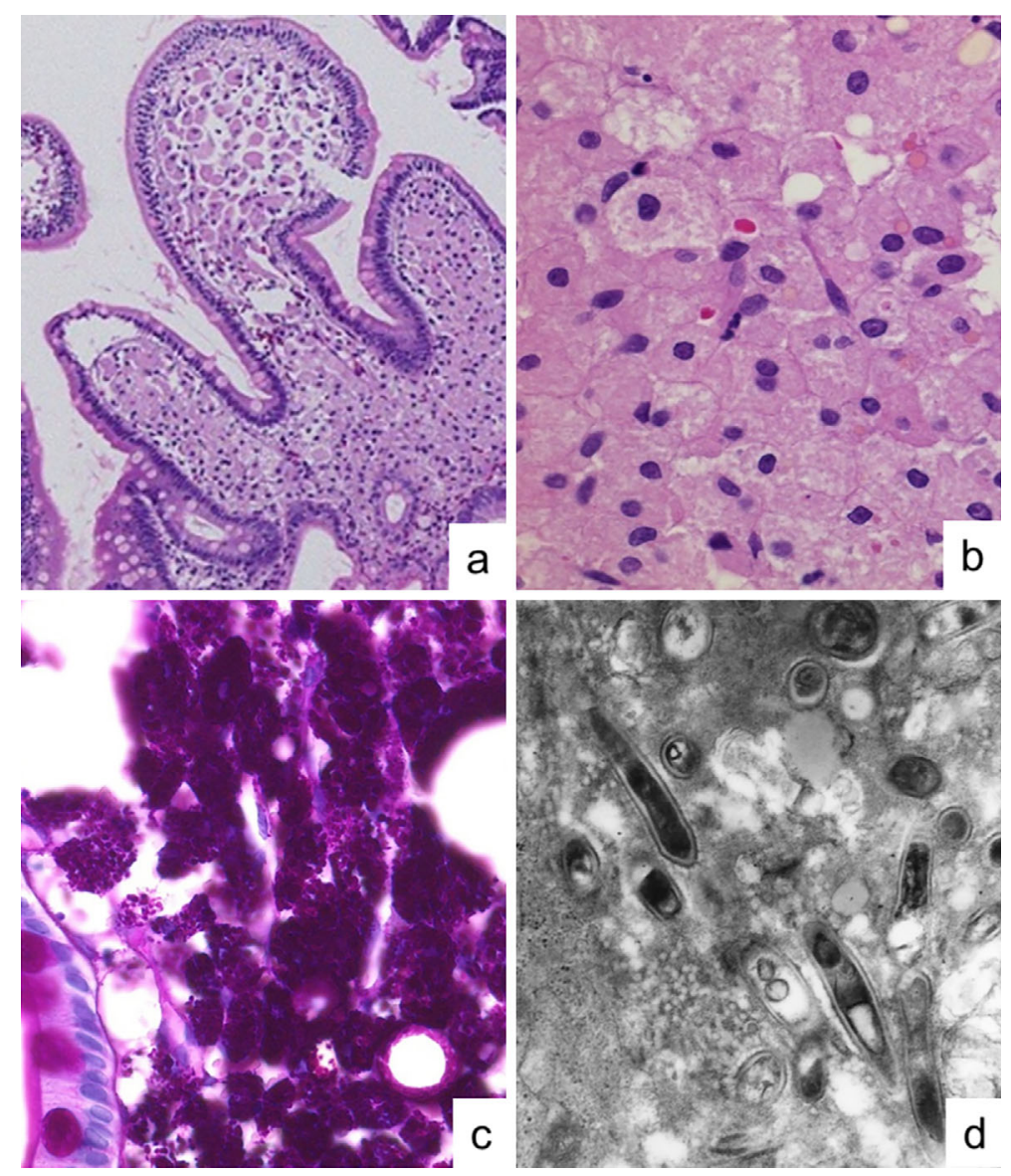

Figure 2. Histopathologic findings. (a) (b) Hematoxylin and Eosin staining $[(a) \times 40$, (b) $\times 400]$. Foamy macrophages are present in the epithelial villi of the duodenal mucosa (arrow). (c) Periodic acid-Schiff $($ PAS) staining $(\times 400)$. Numerous PAS-positive macrophages are observed infiltrating the lamina propria of the duodenum. (d) Electron micrograph of the duodenal mucosa $(\times 20,000)$ showing numerous rod-shaped bacilli with distinctive trilaminar cell walls characteristic of Tropheryma whipplei.

rium in the macrophages was first detected by electron microscopy in 1961 (21), while the $16 \mathrm{~S}$ ribosomal RNA of $T$. whipplei was identified in 1992 (22). The first successful cultivation of the Whipple bacillus was performed in $2000(23)$.

The route of infection for T. whipplei is unknown, but the bacterium is thought to exist in the general environment. Studies using polymerase chain reaction have found $T$. whipplei DNA in sewage plant effluent and human stool (1). It is known that patients with the disease have a higher frequency of human leukocyte antigen (HLA)-B27 than the general population, but no causal association between the presence of HLA-B27 and infection susceptibility has been demonstrated (24).

Whipple's disease is characterized by two stages: a prodromal stage and a much later steady-state stage. The prodromal stage is marked by protean symptoms and nonspecific chronic findings, mainly arthralgia and arthritis. The steady-state stage is typified by weight loss and/or diarrhea; occasionally, there are other manifestations, as many organs can be involved $(1,2)$. Our patient's anorexia and weight loss were consistent with the typical gastrointestinal symp- toms of the steady-state stage. Involvement of the abdominal lymph nodes, especially the mesenteric and periaortic nodes is not uncommon, but peripheral lymphadenopathy is rare (1). Our patient had abdominal lymphadenopathy that responded to antibiotic therapy and disappeared.

Given the broad differential diagnoses and the disease's rarity in Japan, Whipple's disease can be difficult to diagnose $(6,9)$. The differential diagnoses include inflammatory rheumatic diseases, malabsorption with small intestine involvement (e.g., celiac disease, sarcoidosis, and lymphoma), Addison's disease, and connective tissue disorders (1). In our patient, we considered the possibility of lymphoma (Castleman's disease) because of the abdominal lymphadenopathy and high levels of sIL-2R and IL-6; therefore, we started oral prednisolone. However, Whipple's disease is thought to progress rapidly when patients receive immunosuppressive therapy, such as corticosteroids or tumor necrosis factor antagonists (25). In our patient, the oral prednisolone may have caused an exacerbation of the symptoms of Whipple's disease.

The endoscopic examination of patients with classic Whipple's disease reveals pale yellow, shaggy mucosa alter- 


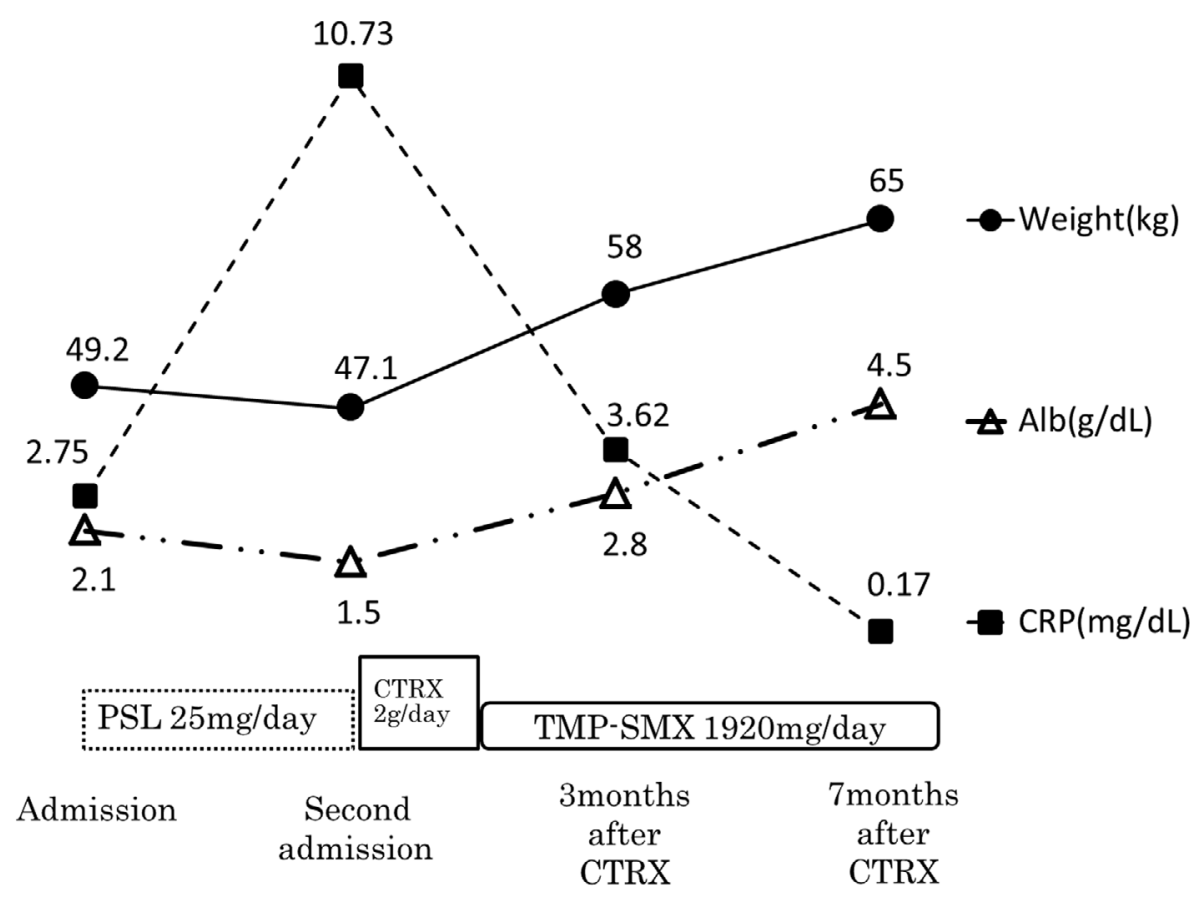

Figure 3. Clinical course after first admission. CTRX: ceftriaxone, PSL: prednisolone, TMP-SMX: trimethoprim-sulfamethoxazole

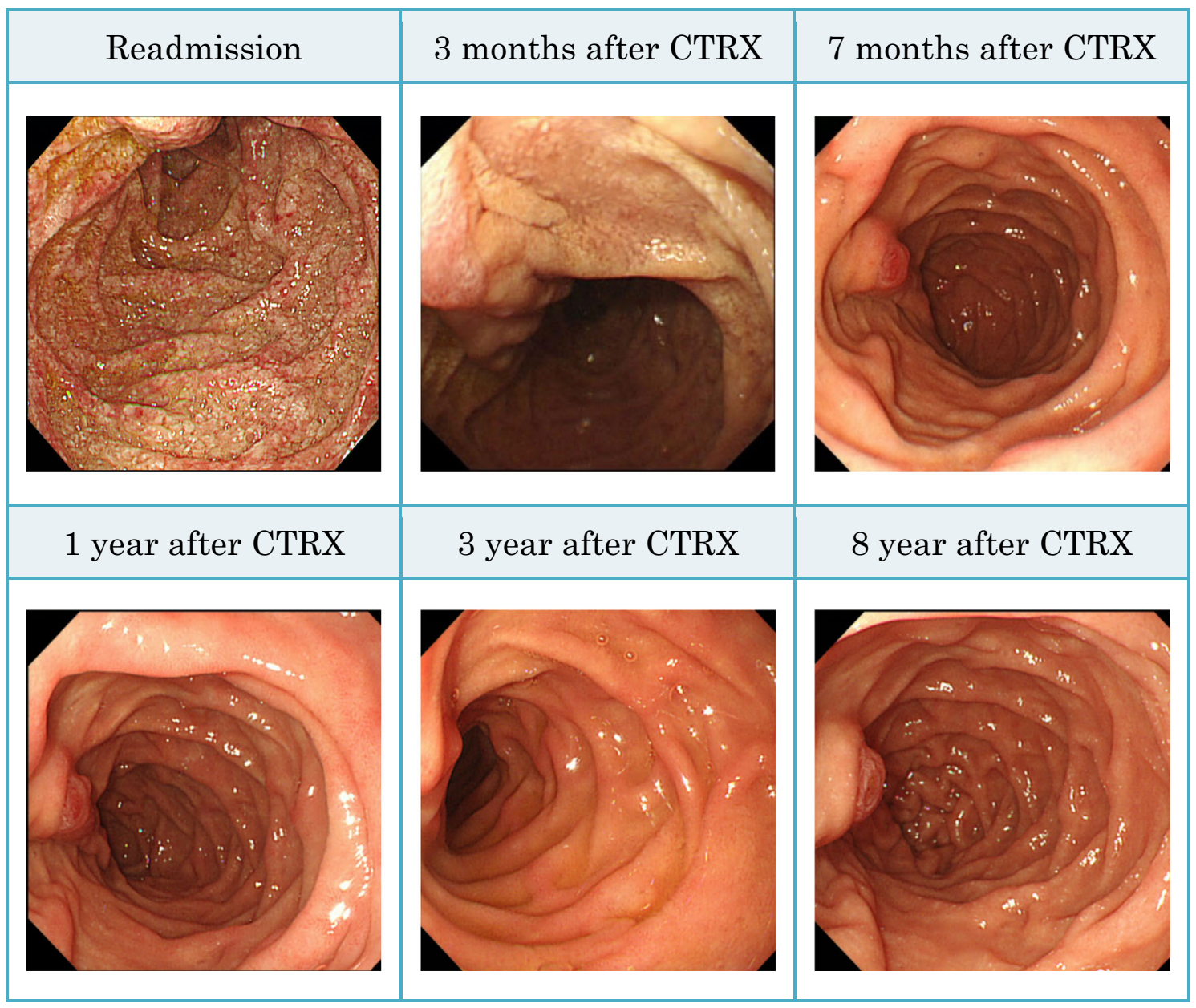

Figure 4. Upper gastrointestinal endoscopy on follow-up. Changes in the duodenal mucosa were improved in the early stage of treatment and never recurred. CTRX: ceftriaxone 


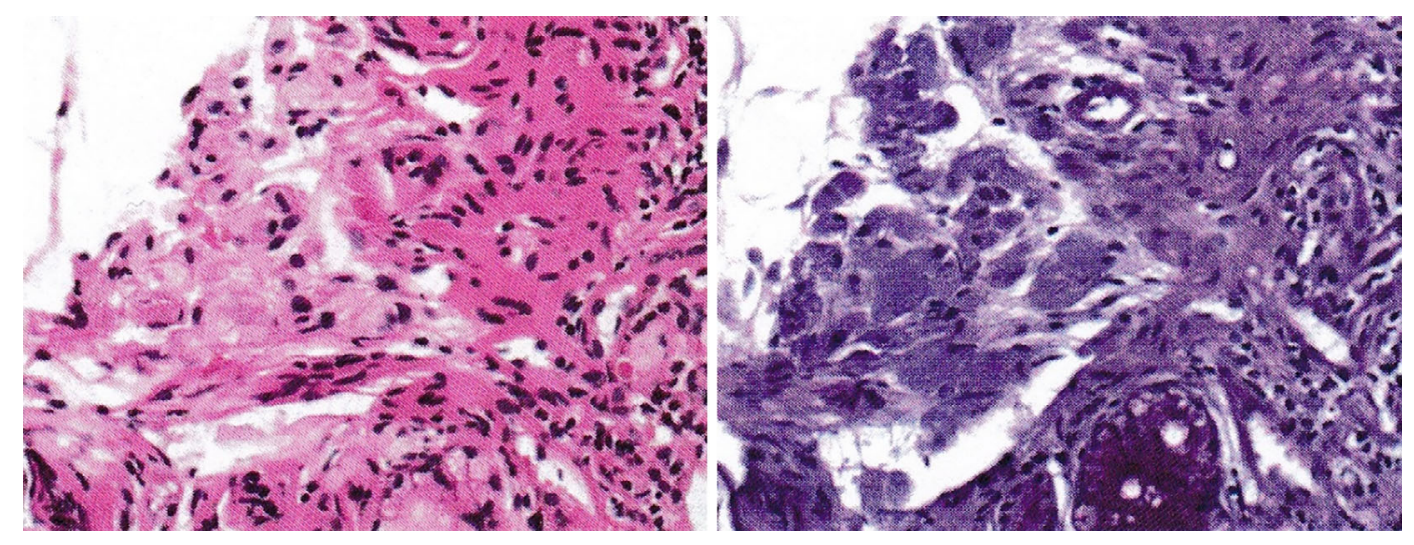

Figure 5. Histopathologic findings at the 8-year follow-up. (a) Microscopy of the duodenal mucosa with Hematoxylin and Eosin staining $(\times 100)$. Numerous foamy macrophages are noted. (b) Periodic acid-Schiff (PAS) staining (×100). Numerous PAS-positive macrophages are observed.

Table 2. Cases of Whipple's Disease in Japan Reported in the Literature.

\begin{tabular}{|c|c|c|c|c|c|c|c|}
\hline \multirow{2}{*}{ Reference } & \multirow{2}{*}{$\begin{array}{l}\text { Age (y) } \\
\text { /Sex }\end{array}$} & \multirow{2}{*}{ Affected organs } & \multicolumn{3}{|c|}{ Diagnostic Tools } & \multirow{2}{*}{ Treatment } & \multirow{2}{*}{ Prognosis } \\
\hline & & & PAS & EM & PCR & & \\
\hline (4) & $45 / \mathrm{M}$ & GI, Heart, Joints, LN & + & - & I & Tetracycline & Alive $(2 \mathrm{~m})$ \\
\hline (5) & $56 / \mathrm{M}$ & GI, Heart, Joints, LN & + & + & l & Observation & $\operatorname{Dead}(2 \mathrm{y})$ \\
\hline (6) & $52 / \mathrm{M}$ & GI & + & + & + & CTRX, TMP-SMX & Alive (1y) \\
\hline (7) & $54 / \mathrm{M}$ & GI, LN & + & - & - & CTRX, TMP-SMX & Alive $(2 \mathrm{y})$ \\
\hline (8) & $50 / \mathrm{M}$ & GI, Brain & + & + & + & CTRX, PCG, TMP-SMX & Alive (10y) \\
\hline (9) & $36 / \mathrm{F}$ & GI, Heart, Brain & + & l & + & CTRX, TMP-SMX & Alive (1y) \\
\hline (10) & $54 / \mathrm{F}$ & GI, Heart, LN, Spleen & + & l & + & CTRX, TMP-SMX & Alive $(2 \mathrm{y})$ \\
\hline (11) & $24 / \mathrm{F}$ & GI & - & - & + & CTRX, TMP-SMX & Alive (8m) \\
\hline (12) & $76 / \mathrm{M}$ & GI, LN & + & l & / & CTRX, TMP-SMX & Alive (1.5y) \\
\hline (13) & $7 \mathrm{X} / \mathrm{M}$ & GI & + & + & / & CTRX, TMP-SMX, CFPN-PI & Alive $(2 \mathrm{~m})$ \\
\hline (14) & $50 / \mathrm{M}$ & GI & + & + & + & CTRX, TMP-SMX & Alive $(2 \mathrm{~m})$ \\
\hline Current case & $72 / \mathrm{M}$ & GI, LN & + & + & I & CTRX, TMP-SMX & Alive (8y) \\
\hline
\end{tabular}

M: male, F: female, GI: gastrointestinal tract, LN: lymph node, PAS: periodic acid-Schiff staining, EM: electron microscopy, PCR: polymerase chain reaction, +: positive, -: negative, /: no result, CTRX: ceftriaxone, PCG: penicillin G, TMP-SMX: trimethoprim-sulfamethoxazole, CFPN-PI: cefcapene pivoxil, m: month, y: year

nating with eroded, erythematous, or mildly friable mucosa in the duodenum and/or jejunum $(1,24)$. It is reported that high-magnification endoscopy and narrow-band imaging observation can help visualize the mucosal characteristics typical of Whipple's disease, including edematous and engorged duodenal villi (26).

Massive infiltration of PAS-positive macrophages in the lamina propria of the duodenum or jejunum is the most notable pathophysiologic characteristic of the disease (27). Several studies have also demonstrated a defective macrophage function in patients with Whipple's disease. Moos et al. showed that T. whipplei triggers the differentiation of monocytes to alternative-activated macrophages (M2 macrophages); this subclass of macrophages may aid in the survival and replication of $T$. whipplei $(27,28)$. The sensitivity of the PAS staining of small bowel biopsies ranges from $71 \%$ to $78 \%$ for diagnosing Whipple's disease. In addition, Mycobacterium avium complex, which also stains PASpositive, should be considered as a possible differential diagnosis (29).
The confirmation of T. whipplei by electron microscopy or DNA identification by polymerase chain reaction (PCR) is mandatory for a definitive diagnosis (30). T. whipplei has a unique trilamellar cell wall that can be detected via electron microscopy, and this is regarded as an important diagnostic finding. However, it requires a longer detection time. PCR has become the second cornerstone in the diagnosis of Whipple's disease in recent years and should be carried out along with a histological examination. Conventional PCR comprises the detection of the specific 16S rRNA of the bacterium. More recent methods using quantitative real-time PCR have demonstrated higher sensitivity, but they are only available in special centers (28).

In Japan, PAS staining of the intestinal mucosa is positive in almost all cases; however, electron microscopy and PCR are added for the confirmation of a diagnosis (Table 2). Recently, PCR has been used to make a diagnosis in most cases, and there have been several reports describing the usefulness of PCR in making a diagnosis $(10,11,14)$. PCR is rapid, specific, and sensitive (10), so we should recognize 
it as an indispensable tool for obtaining a definitive diagnosis. In our patient, although we recognized characteristic findings on PAS staining and electron microscopy, specification of the bacteria using PCR was not performed, which should be regarded as a limitation of this case.

Without treatment, Whipple's disease is fatal. The recommended treatment is $160 \mathrm{mg}$ TMP and $800 \mathrm{mg}$ SMX twice a day for 1 to 2 years, which is usually preceded by the parenteral administration of streptomycin ( $1 \mathrm{~g}$ daily) with penicillin $\mathrm{G}$ (1.2 million $\mathrm{U}$ daily) or CTRX (2 g daily) for 2 weeks $(1,24,30)$. In order to prevent nervous system recurrence, antibiotics capable of crossing the blood-brain barrier are desirable, although this recommendation is not based on data from any therapeutic trial. In most of the cases reported in Japan, CTRX and TMP-SMX were administered for treatment (Table 2).

The clinical course after starting treatment is generally good in most Japanese cases, but there are few reports that include long-term follow-up. Therefore, we believe that our ability to perform long-term follow-up in the present patient is particularly meaningful. We performed repeated follow-up gastrointestinal endoscopy, confirming that the changes in the duodenal mucosa improved in the early stage of treatment, whereas macrophage infiltration in the lamina propria of the duodenum persisted. Uryu et al. reported a case with neurologic recurrence of Whipple's disease, where the accumulation of macrophages in the lamina propria of the duodenum continued for six years, even after the symptoms had disappeared (9). Although the relevance of this finding to the clinical course and risk of recurrence is unknown, it may suggest that macrophage replication and the antiinflammatory function of the lamina propria remain abnormal. For this reason, our patient has continued receiving oral TMP-SMX with careful follow-up.

In summary, we herein described a patient with Whipple's disease who was successfully treated with antibiotic therapy. Although his clinical symptoms and endoscopic findings rapidly improved, the accumulation of macrophages in the lamina propria of the duodenum persisted. This finding suggests a lack of an anti-inflammatory function may improve the survival of $T$. whipplei, and as such, a long-term followup is indicated.

The authors state that they have no Conflict of Interest (COI).

\section{References}

1. Fenollar F, Puéchal X, Raoult D. Whipple's disease. N Engl J Med 356: 55-66, 2007.

2. Puéchal X. Whipple disease and arthritis. Curr Opin Rheumatol 13: 74-79, 2001.

3. Enzinger FM, Helwig EB. Whipple's disease: a review of the literature and report fifteen patients. Virchows Arch Pathol Anat Physiol Klin Med 336: 238-269, 1963.

4. Naramoto J, Tamechika Y, Niizeki H, et al. A case of Whipple disease with non-specific multiple ulcer of the intestine. I to Cho (Stomach and Intestine) 11: 227-231, 1976 (in Japanese, Abstract in English).

5. Tsuru T, Hamada T, Honda M, et al. An autopsy case of Whipple disease. Saishin Igaku 34: 1993-1997, 1979 (in Japanese).

6. Yogi T, Hokama A, Kinjo F, et al. Whipple's disease: the first Japanese case diagnosed by electron microscopy and polymerase chain reaction. Intern Med 43: 566-570, 2004.

7. Kawasaki K, Kobayashi H, Kurahara K, et al. Whipple's disease with findings of NBI magnifying observation and capsule endoscopy, report of a case. I to Cho (Stomach and Intestine) 46: 311319, 2011 (in Japanese, Abstract in English).

8. Watanabe D, Kakimoto T, Kodama K, et al. Whipple's disease. Nihon Shokakibyo Gakkai Zasshi (Jpn J Gastro-enterol) 110: 9981006, 2013 (in Japanese, Abstract in English).

9. Uryu K, Sakai T, Yamamoto T, et al. Central nervous system relapse of Whipple's disease. Intern Med 51: 2045-2050, 2012.

10. Yajima N, Wada R, Kimura S, et al. Whipple disease diagnosed with PCR using formalin-fixed paraffin-embedded specimens of the intestinal mucosa. Intern Med 52: 219-222, 2013.

11. Kono M, Yamamoto K, Nagamatsu M, et al. Use of polymerase chain reaction in the diagnosis of Whipple's disease. J Infect Chemother 21: 885-888, 2015.

12. Domori K, Sato A, Nakajima N, et al. Whipple's disease with typical endoscopic features report of clinically diagnosed case. I to Cho (Stomach and Intestine) 50: 1443-1449, 2015 (in Japanese, Abstract in English).

13. Hirano A, Hirai F, Takada Y, et al. Whipple's disease diagnosed based on imaging, reported of a case. I to Cho (Stomach and Intestine) 51: 1626-1634, 2016 (in Japanese, Abstract in English).

14. Nagasue $T$, Kurahara $K$, Yaita $H$, et al. Whipple's disease diagnosed using electron microscopy and polymerase chain reaction. Nihon Shokakibyo Gakkai Zasshi (Jpn J Gastro-enterol) 113: 1894-1900, 2016 (in Japanese, Abstract in English).

15. Suehara M, Niiyama T, Higuchi I, et al. The first Japanese case of CNS Whipple's disease. Clinical Neurology 39: 252, 1999 (Abstract in Japanese).

16. Minagawa K, Aramaki K, Kikuchi H, et al. A case of Whipple disease with clincal features of polyarteritis nodosa. Ryumachi $\mathbf{4 3}$ : 464, 2003 (Abstract in Japanese).

17. Iwamura S, Uchita K, Kono N, et al. A Japanese case of Whipple disease diagnosed by immunohistochemistry. Nihon Shokakibyo Gakkai Zasshi (Jpn J Gastro-enterol) 103: A839, 2006 (Abstract in Japanese).

18. Tatsuki M, Ishige W, Hatori R, et al. Whipple disease of child which diagnosed electron microscopy and PCR. Nihon Shounika Gakkai Zasshi (Jpn J Gastro-enterol) 117: 329, 2013 (Abstract in Japanese).

19. Whipple GH. A hitherto undescribed disease characterized anatomically by deposits of fat and fatty acids in the intestinal and mesenteric lymphatic tissues. Bull Johns Hopkins Hosp 18: 382391, 1907.

20. Black-Schaffer B. The tinctorial demonstration of a glycoprotein in Whipple's disease. Proc Soc Exp Biol Med 72: 225-227, 1949.

21. Chears WC Jr, Ashworth CT. Electron microscopic study of the intestinal mucosa in Whipple's disease. Demonstration of encapsulated bacilliform bodies in the lesion. Gastroenterology 41: 129138, 1961.

22. Relman DA, Schmidt TM, MacDermott RP, Falkow S. Identification of the uncultured bacillus of Whipple's disease. $\mathrm{N}$ Engl $\mathrm{J}$ Med 327: 293-301, 1992.

23. Raoult D, Birg M, La Scola B, et al. Cultivation of the bacillus of Whipple's disease. N Engl J Med 342: 620-625, 2000.

24. Marth T, Raoult D. Whipple's disease. Lancet 361: 239-246, 2003.

25. Mahnel R, Kalt A, Ring S, Stallmach A, Strober W, Marth T. Immunosuppressive therapy in Whipple's disease patients is associated with the appearance of gastrointestinal manifestations. Am J Gastroenterol 100: 1167-1173, 2005. 
26. Neumann H, Mönkemüller K, Neurath MF, et al. Advanced endoscopic imaging using narrow-band imaging for diagnosis of Whipple's disease. Endoscopy 44 (Suppl): E101, 2012.

27. Moos V, Schmidt C, Geelhaar A, et al. Impaired immune functions of monocytes and macrophages in Whipple's disease. Gastroenterology 138: 210-220, 2010.

28. Obst W, von Arnim U, Malfertheiner P. Whipple's disease. Viszeralmedizin 30: 167-172, 2014.

29. Ramzan NN, Loftus E Jr, Burgart LJ, et al. Diagnosis and monitoring of Whipple disease by polymerase chain reaction. Ann In- tern Med 126: 520-527, 1997.

30. Keinath RD, Merrell DE, Vlietstra R, Dobbins WO 3rd. Antibiotic treatment and relapse in Whipple's disease. Long-term follow-up of 88 patients. Gastroenterology 88: 1867-1873, 1985.

The Internal Medicine is an Open Access article distributed under the Creative Commons Attribution-NonCommercial-NoDerivatives 4.0 International License. To view the details of this license, please visit (https://creativecommons.org/licenses/ by-nc-nd/4.0/).

(C) 2018 The Japanese Society of Internal Medicine Intern Med 57: 1707-1713, 2018 